\title{
Estratégias ecofisiológicas de espécies de Volchisiaceae da mata ciliar do rio lençóis, Chapada Diamantina, Bahia
}

\author{
Josevânia Carneiro de Oliveira ${ }^{\mathbf{1}}$; Lia d' Afonsêca Pedreira de Miranda ${ }^{\mathbf{2}}$ \\ ${ }^{1}$ Bolsista de Iniciação Cientifica, PIBIC, Graduanda em Ciências Biológicas, Universidade Estadual de Feira de Santana. \\ Email: vaniauefs.bio@hotmail.com \\ ${ }^{2}$ Orientadora do departamento de Ciências Biológicas, Universidade Estadual de Feira de Santana. Av. Transnordestina, s/n, \\ Novo Horizonte, 44036-900, Feira de Santana, BA. Email: liapmiranda@ yahoo.com.br
}

PALAVRAS-CHAVE: Potencial hídrico, densidade da madeira e atributos foliares

\section{INTRODUÇÃO}

Nosso trabalho contempla a floresta ciliar do rio Lençóis, no Município de Lençóis, Bahia, abrangendo as espécies da família Vochysiaceae presentes neste ambiente.

Vochysiaceae possui distribuição neotropical, inclui oito gêneros e cerca de 250 espécies, das quais, mais da metade estão em Vochysia. No Parque Nacional da Chapada Diamantina e no seu entorno foram identificadas três espécies distribuídas em dois gêneros. As espécies, Vochysia pyramidalis Mart e Qualea cypthanta var. marginata (Miq) Stafl estão frequentemente associadas as florestas ciliares e floresta de encosta (FUNCH, 2008).

As respostas de planta à heterogeneidade espaço-temporal das condições ambientais são na maioria das vezes, moduladas por características morfológicas e fisiológicas (MATTOS et al. 2004; GARNIER et al. 2001), que podem refletir as estratégias ecológicas das espécies (KATTGE et al. 2011).

Considerando o reconhecimento do significado funcional dos parâmetros morfofuncionais como: massa da folha por unidade de área (MFA) (REICH et al. 1992), suculência (SUC) (KLUGE \& TING 1978), densidade (DEN) e espessura (ESP)

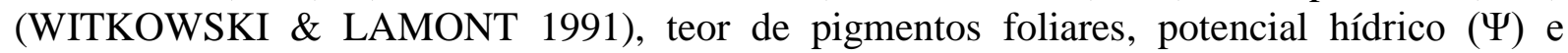
densidade da madeira que são bons descritores do desempenho de plantas e são utilizadas em estudos que caracterizam o desempenho ecofisiológico de espécies vegetais frente a sazonalidade (ROSADO \& de MATTOS 2007; ROSSATO 2010; MIRANDA et al 2011; PÉREZ-HARGUINDEGUY 2013; MORAIS et al 2017; SCHOLZ et al. 2007). Delineamos este trabalho, cujo objetivo desse foi investigar as estratégias ecofisiológicas de $V$. pyramidalis e $Q$. cryptantha, espécies importantes de florestas na Chapada Diamantina, para responder as seguintes questões: a) a análise dos caracteres morfofuncionais explica o padrão fenológico foliar divergente nas espécies? b) a densidade da madeira interfere a manutenção do status hídrico nas espécies avaliadas?

\section{METODOLOGIA}

O estudo foi desenvolvido na floresta ciliar do rio Lençóis, uma floresta submontana sempre verde, situada entre as coordenadas $12^{\circ} 33^{\prime} 34^{\prime \prime} \mathrm{S}$ e $41^{\circ} 24^{\prime} 15^{\prime \prime} \mathrm{W}$. Os dados ambientais (precipitação, temperatura e umidade relativa do ar foram obtidos através do site do Instituto Nacional de Meteorologia (INMET), registrados na Estação Meteorológica de Lençóis.

Os parâmetros morfofuncionais foram mensurados em meses de seca (setembro) e chuva (dezembro). Nas medidas do potencial hídrico antes do amanhecer ( $\left.\Psi_{\mathrm{PD}}\right)$ e após o meio dia $\left(\Psi_{\mathrm{PM})}\right.$ utilizou-se câmara de pressão de Scholander e foi calculada a amplitude diária $(\Delta \Psi)$. Os atributos foliares: massa da folha por unidade de área (MFA), suculência (SUC) e) densidade (DEN) foram avaliados.

Os teores dos pigmentos foram determinados em quatro indivíduos, através do método indireto, utilizando-se clorofilômetro digital (CLROROFILOG FALKER -0,1 ICF) em 02 
folhas maduras (completamente expandidas) e expostas ao sol.

A razão de área foliar (RAF, $\mathrm{cm}^{2} \cdot \mathrm{g}^{-1}$ ) e fração de massa foliar (FMF, $\mathrm{g} \cdot \mathrm{g}^{-1}$ ), foram medidas em dois indivíduos de cada espécie, foram cortados dois ramos a partir da base e posteriormente separados em caule e folhas para serem digitalizadas com um scanner de mesa em uma resolução de 100dpi, estimando a área total a partir do programa Scion Image 6.0. Após, as folhas e os ramos foram colocados em estufa a $55^{\circ} \mathrm{C}$ durante cinco dias para obtenção da massa seca. A partir dos valores de massa seca foram obtidos os parâmetros de FMF dividindo-se a massa de folhas pela massa total do ramo e RAF, a partir da divisão da área total de folhas do ramo pela massa total (massa das folhas + massa do ramo) do mesmo.

Os parâmetros morfofuncionais citados acima foram submetidos à análise de variância e teste de Tukey $(p<0,05)$. A densidade da madeira foi avaliada no período chuvoso em cinco "peças" com $10 \mathrm{~cm}$ de comprimento e $5 \mathrm{~cm}$ de diâmetro, coletadas de cinco indivíduos de cada espécie, segundo Trugilho et al. (1990).

\section{RESULTADOS E DISCUSSÃO}

Tanto em $Q$. cryptantha, quanto em $V$. pyramidalis $o \Psi_{\mathrm{PD}}$ e o $\Psi_{\mathrm{PM}}$ diferiram $(\mathrm{p}<0,05)$ entre as avalições de seca e chuva, com valores maiores no período chuvoso. Em Vochysia pyramidalis houve variação no $\Delta \Psi$, com as maiores amplitudes sendo registradas no período seco. O aumento do potencial hídrico no período chuvoso é esperado em espécies lenhosas em geral e já foi registrado na maioria da espécies avaliadas na área de estudo (MIRANDA et al. 2011; MORAIS, 2015). A comparação entre as espécies mostrou que houve variação apenas no $\Psi_{\mathrm{PD}}$ e no $\Delta \psi$ durante o período seco, com $V$. pyramidalis mostrando os valores mais elevados. Segundo Miranda et al (2011) esta espécie é sempre encontrada muito próxima a calha dos rios ou próxima a córregos da região, os autores ainda sugerem que o elevado $\Delta \psi$ indica elevado fluxo transpiratório o que pode estar relacionado a sua aparente dependência por água evidenciada por sua localização. A espécie $Q$. cryptantha tem padrão semidecidual e a queda foliar pode ser a estratégia utilizada pela espécies para reduzir o fluxo transpiratório no período seco. Nas duas espécies foram registrados valores de $\Psi_{\text {PD }}$ relativamente elevados durante o período seco, o que segundo Prado et al 2004 é indicativo de recuperação noturna das perdas hídricas ocorridas ao longo do dia.

Considerando os atributos morfológicos, apenas a espessura e a densidade mostraram diferença $(\mathrm{p}<0,05)$, entre os períodos secos e chuvosos, tanto em $Q$. cryptantha quanto em $V$. pyramidalis. Entre as espécies, somente suculência e a espessura variaram nos períodos de avaliação com os maiores valores registrados em $V$. pyramidalis. A ocorrência de folhas com maior espessura no período mais seco já foi registrada em ambientes pobres em recursos como o solo litólico da floresta ciliar (observações pessoais) e em plantas de restinga (ROSADO \& de MATTOS, 2007). A densidade da folha mostrou-se elevada especialmente no período chuvoso, folhas com maior densidade tem relação com esclerofilia, resistência a transpiração (ROSADO 2006), e as torna mais rígidas e menos palatáveis a herbívoros (CORRÊA et al. 2008).

Em $Q$. cryptantha, os teores de clorofila $b$ e clorofilas totais mostraram diferença $(\mathrm{p}<0,05)$ entre as avaliações realizadas na seca e chuva, sendo mais elevados nas medidas tomadas durante o período chuvoso. $\mathrm{E}$ em $V$. pyramidalis os teores de pigmentos não mostraram diferença entre os períodos de avaliação. Entre as espécies, no período seco a clorofila $\mathrm{a}, \mathrm{b}$ e total variaram significativamente, com valores mais elevados em $V$. pyramidalis e no período chuvoso não houve variação. $\mathrm{O}$ teor de clorofilas nas folhas é indicativo da capacidade de assimilação de carbono em plantas, podendo também fornecer informações relevantes sobre variações do estado fisiológico das plantas em relação as 
estratégias de resposta para condições de estresse (SIMS \& GAMON, 2002). Sugere-se que a maior assimilação de carbono no período chuvoso em $Q$. cryptantha seja devida a necessidade de fotoassimilados para a frutificação, conforme foi observado ao longo de três anos, a maior concentração de frutos ocorre nessa estação. Embora as espécies sejam da mesma família, apresentaram diferenças significativas, $V$. pyramidalis obteve maiores teores de pigmentos mesmo no período seco o que permite a manutenção de uma copa bem mais robusta que $Q$. cryptantha e, segundo Miranda (2007), mantém um elevado percentual de folhas maduras ao longo do ano.

Ambas as espécies apresentaram alta densidade da madeira, com maior proporção de água saturada em $V$. pyramidalis. Estes resultados sugerem que não apresentam reservatórios hídricos no caule (BORCHERT 1994).

A fração de massa foliar (FMF) foi maior no período chuvoso que na seca tanto em $Q$. cryptantha como $V$. pyramidalis. Entretanto a razão de área foliar (RAF) em $Q$. cryptantha não diferiu entre as avaliações e em $V$. pyramidalis o valor no período chuvoso foi mais elevada. Entre as espécies, tanto no período seco quanto no chuvoso apenas a FMF variou, sendo que os valores mais elevados em ambos os períodos foram registrados em $V$. pyramidalis. Cerqueira (2009) trabalhando com espécies arbóreas em floresta montana, atribuiu o aumento da RAF a disponibilidade hídrica, ideia reforçada pelo fato de que comportamento semelhante foi observado em todas as espécies estudadas na área.

\section{CONSIDERAÇÕES FINAIS}

Os valores da amplitude do potencial hídrico mostram que ambas as espécies mostram maior fluxo transpiratório durante a seca e usam estratégias diferenciadas para a manutenção do estado hídrico neste período, comprovado pelo potencial ao amanhecer relativamente alto. A espécie $Q$. cryptantha usa como estratégia a perda de parte de suas folhas no período seco (semideciduidade) e $V$. pyramidalis sua distribuição em locais com maior disponibilidade de água (padrão perenifólio episódica) com brotamento concentrado em determinada época do ano.

\section{REFERÊNCIAS}

1. BORCHERT, R. Soil and stem water storage determine phenology and distribution of tropical dry forest trees. Ecology v. 75, p. 1437-1449, 1994.

2. CERQUEIRA, CO. Fenologia, caracteres morfológicos foliares e dispersão em uma floresta montana, Serra da Bacia, Palmeiras, Chapada Diamantina, Bahia, Brasil. Tese de Doutorado - Universidade Estadual de Feira de Santana, Feira de Santana, Bahia, 2009.

3. CORREA PG, PIMENTEL RM de M, CORTEZ JS de A, XAVIER HS. Herbivoria e anatomia foliar em plantas tropicais brasileiras. Ciência e Cultura v. 60 , n. 3, p. 5457, 2008.

4. FUNCH, LS. Florestas da região Norte do Parque Nacional da Chapada Diamantina e seu entorno. Pp. 63-77. In: Funch, L.S.; et al. (orgs.). Serra do Sincorá: Parque Nacional da Chapada Diamantina. Feira de Santana. Radami Editora Gráfica, 2008.

5. GARNIER, E.; LAURENT, G.; BELLMAN, A.; DEBAIN, S.; BERTHELIER, P.; DUCOUT, B.; ROUMET, C. \& NAVAS, M.L. Consistency of species ordenação based on functional leaf traits. New Phytologist, v. 152, p. 69-83, 2001.

6. KATTGE, J. TRY - a global database of plant traits. Global Change Biology, v. 17, p. 2905-2935, 2011. 
7. KLUGE, M. \& TING, IP. Crassulacean Acid Metabolism: Analysis of an Ecological Adaptation. Berlin, Springer- Verlag, 1978.

8. MATTOS, EA de; BRAZ, MIG; CAVALIN, PO; ROSADO, BHP; GOMES, JM.; MARTINS, LST \& ARRUDA, RCO. Variação espacial e temporal em parâmetros fisioecológicos de plantas. Pp. 99-116. In: C.F.D. Rocha; F.A. Esteves \& F.R. Scarano (eds.). Pesquisas de longa duração na restinga de Jurubatiba. Ecologia, história natural e conservação. São Carlos, 2004.

9. MIRANDA LAP. Fenologia de cinco espécies arbóreas em matas ciliar e de encosta na região de Lençóis, Chapada diamantina, Bahia, Brasil. Tese (doutorado) Universidade Estadual de Feira de Santana. Feira de Santana, 2007.

10. MIRANDA LAP; VITÓRIA AP; FUNCH LS. Leaf phenology and water potential of five arboreal species in gallery and montane forests in the Chapada Diamantina; Bahia; Brazil. Environmental and Experimental Botany, v. 70, n. 2-3, p. 143-150, 2011.

11. MORAES, ACS. Fenodinâmica e Caracteres Morfofuncionais em Espécies de Myrtaceae da Chapada Diamantina, BR. Tese (doutorado) Universidade Estadual de Feira de Santana, Feira de Santana, 2015.

12. PÉREZ-HARGUINDEGUY, N; DÍAZ, S; GARNIER, E. 2013. New handbook for standardised measurement of plant functional traits worldwide. Australian Journal of Botany v. 61, p. 137-234.

13. PRADO, CHBA, WENHUI, Z, ROJAS, MHC \& SOUZA, GM. Seasonal leaf gas exchange and water potential in a woody cerrado species community. Brazilian Journal of Plant Physiology v. 16, p. 7-16, 2004.

14. REICH, PB, WALTERS, MB \& ELLSWORTH, DS. Leaf lifespan in relation to leaf, plant, and stand characteristics among diverse ecosystems. Ecological Monographs v. 62, p. 365-392, 1992.

15. ROSADO BHP \& MATTOS, EA de. Variação temporal de características morfológicas de folhas em dez espécies do Parque Nacional da Restinga de Jurubatiba, Macaé, RJ, Brasil. Acta Botânica Brasílica v. 21 n. 3, p. 741-752, 2007.

16. ROSADO, B. H. P. A importância da inclusão de diferentes dimensões de variação de características morfo-fisiológicas e de crescimento para o entendimento dos padrões de dominância de plantas de restinga. Dissertação (Mestrado), Universidade Federal do Rio de Janeiro, 2006.

17. ROSSATTO, D. R.; TAKAHASHI, F. S. C.; SILVA, 1. C. R.; FRANCO, A. C. Características funcionais de folhas de sol e sombra de espécies arbóreas em uma mata de galeria no Distrito Federal, Brasil. Acta bot. Bras, v. 24, n. 3, p. 640-647, 2010.

18. SCHOLZ, FG.; BUCCI, S. G.; GOLDSTEIN, G.; MEINZER, F. C.; FRANCO, A. C.; Miralles-Wilhelm, F. Biophysical properties and functional significance of stem water storage tissues in Neotropical savanna trees. Plant, Cell \& Environment, v. 30, p. 236-248, 2007.

19. SIMS, DA.; GAMON, JA. Relationships between leaf pigment contente and spectral reflectance across a wide range of species, leaf structures and developmental stages. Remote Sensing of Environment, v. 81, p. 337 - 354, 2002.

20. TRUGILHO PF; SILVA DA; FRAZÃO FJL; MATOS JLM. Comparação de métodos de determinação de densidade básica em madeira. Acta Amazonica 20:307-319, 1990.

21. WITKOWSKI, E.T.F. \& LAMONT, B.B. Leaf specific mass confounds leaf density and thickness. Oecologia, v. 88, p. 486-493, 1991. 